\title{
RELAÇÃO ENTRE O RETORNO DAS AÇÕES E O ECONOMIC VALUE ADDED (EVA): EVIDÊNCIAS EMPÍRICAS EM COMPANHIAS ABERTAS NO BRASIL ${ }^{1}$
}

\section{RELATIONSHIP BETWEEN STOCK RETURNS AND ECONOMIC VALUE ADDED (EVA): EMPIRICAL EVIDENCES IN BRAZILIAN PUBLIC COMPANIES}

\author{
João Victor Joaquim Santos ${ }^{2}$ \\ Mestrando em Ciências Contábeis pela Universidade Federal do Rio Grande do Norte \\ falarcomjoaovictor@yahoo.com.br \\ orcid.org/0000-0001-5560-6278
}

\section{Adilson de Lima Tavares}

Doutor em Ciências Contábeis pelo Programa Multiinstitucional UnB/UFPB/UFRN

Professor do Programa de Pós-Graduação em Ciências Contábeis da Universidade Federal do Rio Grande do Norte adilson.tavares@uol.com.br orcid.org/0000-0002-7800-9473

\section{Yuri Gomes Paiva Azevedo}

Mestrando em Ciências Contábeis pela Universidade Federal do Rio Grande do Norte yuri azevedo@live.com orcid.org/0000-0002-0830-0214

\section{Raimundo Marciano Freitas Neto}

Mestre em Ciências Contábeis pelo Programa Multiinstitucional UnB/UFPB/UFRN

Professor do Instituto Federal do Rio Grande do Norte

raimundomfn@gmail.com

orcid.org/0000-0002-3319-6260

\section{RESUMO}

Objetivo: Este estudo tem por objetivo investigar a relação entre o valor econômico agregado e o retorno das ações de 178 empresas listadas na Brasil, Bolsa, Balcão (B3).

Fundamento: $\mathrm{O} E V A \circledast$ é uma medida de desempenho que busca expressar a real criação de riqueza de uma empresa, além de ser um dos critérios mais eficientes na avaliação da explicação quantitativa do retorno das ações (Awan, Siddique, \& Sarwar, 2014).

Método: Foi computada a correlação de Spearman, e estimado um modelo de regressão com dados em painel com efeitos aleatórios. Os dados coletados para o cálculo do modelo compreendem o período entre 2010-2015, sendo obtidos através da base de dados Bloomberg®.

\footnotetext{
${ }_{1}$ Artigo recebido em: 09/06/2017. Revisado por pares em: 20/09/2017. Reformulado em: 27/09/2017. Recomendado para publicação em: 27/09/2017 por Luiz Felipe de Araújo Pontes Girão (Editor Geral). Publicado em: 11/10/2017. Organização responsável pelo periódico: UFPB.

${ }^{2}$ Endereço: Av. Sen. Salgado Filho, 3000, Lagoa Nova, Natal/RN, CEP 59078-970.

DOI: http://dx.doi.org/10.18405/recfin201801077
} 
Resultados: Observa-se que, em média, as firmas analisadas têm apresentado retornos negativos e sido destruidoras de valor; e as correlações evidenciam que há relação do EVA® com o retorno das ações, embora em um nível inferior ao do Retorno sobre o Ativo (ROA). Além disso, foi constatado que as variáveis EVA, ROA e Tamanho apresentaram-se positiva e estatisticamente significantes para explicar o retorno contínuo e o retorno anormal das ações.

Contribuições: $\mathrm{O}$ estudo apresenta contribuições relevantes por se tratar de um tema pouco explorado na literatura nacional, evidenciando elementos que contribuem para a criação de valor econômico nas empresas. Ademais, verificou-se que os modelos para retornos contínuos e retornos anormais são convergentes.

Palavras-chave: Valor econômico agregado. Retorno das ações. Desempenho econômico.

\section{ABSTRACT}

Objective: This study aims to investigate the empirical relationship between the Economic Value Added and stock returns of 178 public companies listed on B3.

Background: $\mathrm{EVA} \AA$ is a performance measure that intends to express the effective value creation in a firm, besides being one of the most efficient criteria for quantitative assessment of stock returns (Awan, Siddique, \& Sarwar, 2014).

Method: We performed Spearman correlation and estimated a regression model with panel data and random effects. We collected financial data of the period 2010-2015 on the Bloomberg® database.

Results: It is possible to observe that firms have shown negative returns and value destruction for shareholders. There is a weak, positive correlation between EVA and returns, though the degree of association between ROA and returns has turned out to be stronger. Moreover, the regression models showed that EVA, ROA and Size are positive and significant regressors for our stock sample.

Contributions: This article significantly contributes to the literature because it explores a theme scarcely studied in Brazil, presenting elements that help companies in the process of value creation. Moreover, our models for abnormal returns and continuous returns are convergent.

Keywords: Economic Value Added. Stock returns. Economic performance.

\section{INTRODUÇÃO}

Há um consenso que o principal objetivo de uma empresa é criar valor; por isso, maximizar o valor aos acionistas de uma entidade tornou-se um paradigma corporativo nos últimos anos. Além disso, é cada vez mais perceptível e presente a realidade competitiva em que as empresas estão inseridas, o que faz com que elas desenvolvam práticas com o objetivo de gerar valor, bem como de monitorá-lo. Nesse sentido, no contexto acadêmico, diversos trabalhos têm sido realizados com o objetivo de identificar e analisar os direcionadores de valor de uma empresa, assim como sua contribuição para a criação de valor (O’Byrne, 1997, Kim, 2006, Palliam, 2006, Sharma \& Kumar, 2012, Mostafa \& Dixon, 2013, Tamamy, 2014, Shah, Haldar, \& Rao, 2015, Khan, Aleemi, \& Qureshi, 2016).

Diante disso, surgem diversas estratégias relacionadas à criação de valor, além de diversos métodos de avaliação de desempenho das organizações (Cerqueira, Soares, \& David, 2009), desde indicadores econômico-financeiros tradicionais, que possibilitam uma análise da situação estática do patrimônio, até os de desempenho, que consideram o custo do capital próprio e de terceiros investido no negócio e derivam da necessidade de medir a criação de valor para os acionistas.

Um dos indicadores financeiros mais importantes para empresas ativas em bolsa é o retorno de ações, e os investidores em ações têm buscado uma maneira de prever isso. Um estudo realizado por Stewart (1994) com empresas norte americanas evidenciou que o Valor Econômico Agregado (EVA®) tem superioridade para explicar o retorno das ações, em relação a outras medidas contábeis populares à época. 
O EVA® se apresenta basicamente como o lucro econômico que é adicionado para os proprietários pela administração, ou seja, quando o Valor Econômico Agregado de uma empresa em determinado período é positivo, ela gerou valor ao acionista (Haddad, 2012). O EVA®é uma medida de desempenho que busca expressar a real criação de riqueza de uma empresa, além de ser um dos critérios mais eficientes na avaliação da explicação quantitativa do retorno das ações (Awan et al., 2014).

Alguns estudos na área, entretanto, têm sugerido que não há relação entre o valor econômico agregado e o retorno das ações (Copeland, Dolgoff, \& Moel, 2004, Chaves, Vellani, \& Pimenta, 2012, Ray, 2014, Mosavai, 2015, Khan, Aleemi, \& Qureshi, 2016), ou que o poder explicativo dessa variável é baixo (Visaltanachoti, Luo, \& Yi, 2008, Bastos et al., 2009, Khan, Shah, \& Rehman, 2012). Diante do dissenso encontrado na literatura sobre o tema, tem-se o seguinte problema de pesquisa: há relação entre o EVA® e o retorno de ações listadas na B3? Assim, o presente estudo tem por objetivo investigar a relação empírica entre o EVA® e o retorno de ações listadas na B3.

A motivação para a pesquisa deriva do crescente destaque que o assunto vem tendo no meio empresarial e acadêmico. Além disso, a importância desta pesquisa se justifica pela exploração de elementos que contribuem para a criação de valor econômico nas empresas, tendo em vista que este é um dos maiores desafios e exigências nas empresas.

Outra justificativa para a realização do estudo é o baixo número de ensaios sobre a temática no âmbito nacional, destacando-se as pesquisas realizadas por Bastos et al. (2009), Silva et al., (2009), Medeiros (2009), Chaves et al. (2012) e Costa et al., (2017). Ademais, a maioria dessas pesquisas, como a de Silva et al. (2009), Medeiros (2009), Chaves et al. (2012) e Costa et al. (2017), apresentam amostras que podem não ser tão representativas. Sendo assim, os resultados aqui obtidos podem contribuir para a literatura na área, além de apresentar evidências empíricas sobre a utilização do EVA®.

O presente trabalho está estruturado em cinco seções. Além desta Introdução, encontra-se na próxima seção o referencial teórico, que aborda aspectos relacionados à criação de valor nas empresas, medidas de desempenho, Valor Econômico Agregado, além dos estudos recentes relacionados à área. A terceira sessão apresenta a metodologia utilizada para a análise de dados. Na quarta temse a análise dos resultados obtidos através dos modelos de regressão e, por fim, a quinta parte apresenta as considerações finais, evidenciando as constatações do estudo, assim como as sugestões para futuros trabalhos.

\section{VALOR ECONÔMICO AGREGADO}

Existem diversos indicadores de desempenho que orientam os gestores na busca por resultados que efetivamente contribuam para aumentar o valor da empresa e, consequentemente, a riqueza dos acionistas. No entanto, de acordo com Bastos et al. (2009), a relação entre as métricas de desempenho e valor da empresa ainda se mostra frágil, pois as medidas de desempenho tradicionais não levam em consideração o custo de oportunidade do capital próprio nem o risco do negócio.

Por isso, muitas críticas são atribuídas ao sistema de contabilidade tradicional, visto que essas métricas não contemplavam o fator Valor, através de uma unidade de medida. O economista Alfred Marshall em 1890, já abordava a noção de lucro econômico, no qual considerava o acréscimo dos custos operacionais e o custo de capital investido para se alcançar o lucro real de uma empresa (Burksaitiene, 2009).

Sendo assim, a necessidade de medidas que levam em consideração essas variáveis são importantes para avaliar a criação de valor das entidades. Uma dessas medidas que avaliam a criação de valor nas empresas é o Valor Econômico Agregado, que representa quanto uma empresa lucrou acima do seu custo de capital. Adicionalmente, Bastos et al., (2009) afirmam que o indicador mensura o excesso de retorno que o acionista ganharia comparativamente a outro ativo de risco similar. $\mathrm{O}$ 
EVA® é a medida de desempenho financeiro que mais se aproxima do em capturar o verdadeiro lucro econômico de uma empresa (Haque \& Islam, 2013).

De acordo com Young e O'Byrne (2003), uma das vantagens do EVA® é possibilitar a conexão entre uma medida interna de desempenho e a avaliação realizada pelo mercado de capitais, dessa forma, atestam-se as empresas que o utilizam, de que o esforço gerencial para melhorar esse indicador será ponderado e recompensado de forma coerente com a teoria moderna de finanças.

Adicionalmente, Duarte (2011) afirma que a aproximação com o valor de mercado da empresa, bem como a facilidade no entendimento do conceito e forma de cálculo, que popularizou a sua utilização por diversas empresas ao redor do mundo, são outras vantagens dessa medida. No entanto, o fato de se basear em resultados passados e não incorporar as expectativas futuras são citadas pelo mesmo autor como desvantagens.

Dentre os estudos realizados na área, Ismail (2006), Visaltanachoti et al. (2008) e Bastos et al. (2009) evidenciam a existência da relação do EVA® com o retorno de ações. No entanto, afirmam que outras medidas tradicionais de desempenho como o Retorno sobre o Patrimônio Líquido (ROE), o Retorno sobre o Ativo (ROA), ou o próprio Lucro Líquido da entidade, apresentam maior associação com o retorno de ações do que o Valor Econômico Agregado.

Nessa perspectiva, tendo em vista que o EVA® é considerado como a medida de desempenho que está mais diretamente associada à criação de patrimônio dos acionistas ao longo do tempo (Nakhaei et al, 2016). Diversas pesquisas investigam a relação do Valor Econômico Agregado com o valor das ações, conforme evidenciado no Quadro 1, analisando preço ou retorno.

Quadro 1. Estudos anteriores sobre a relação entre o EVA® e o valor das ações

\begin{tabular}{|c|c|c|}
\hline Autores & Amostra & Principais Resultados \\
\hline $\begin{array}{l}\text { Tortella e Brusco } \\
\text { (2003) }\end{array}$ & $\begin{array}{l}61 \text { firmas listadas na base de } \\
\text { dados Compustat com infor- } \\
\text { mações disponíveis. }\end{array}$ & $\begin{array}{l}\text { Com base em estudo de eventos em diversas janelas } \\
\text { temporais, não foram observados retornos anormais } \\
\text { derivados da adoção do EVA®, aparentemente não } \\
\text { havendo reação do mercado à divulgação do indica- } \\
\text { dor. }\end{array}$ \\
\hline Copeland et al. (2004) & $\begin{array}{l}\text { Todas as firmas pertencentes } \\
\text { ao S\&P500 no período de } 1992 \\
\text { a } 1998 .\end{array}$ & $\begin{array}{l}\text { Não há evidências significativas de relação entre o } \\
\text { EVA® e o retorno aos acionistas ou mesmo que o } \\
\text { EVA® possa ter um poder explicativo superior ao do } \\
\text { Earnings per share. }\end{array}$ \\
\hline Ismail (2006) & $\begin{array}{l}2.252 \text { observações de firmas } \\
\text { britânicas no período de } 1990 \text { a } \\
1997 \text {. }\end{array}$ & $\begin{array}{l}\text { Os resultados da regressão com dados em painel } \\
\text { apontam que Lucro Líquido e NOPAT estão mais as- } \\
\text { sociados ao retorno das ações do que o EVA®. }\end{array}$ \\
\hline $\begin{array}{l}\text { Visaltanachoti et al. } \\
\text { (2008) }\end{array}$ & $\begin{array}{l}21.000 \text { observações de empre- } \\
\text { sas americanas no período de } \\
2003 \text { a } 2005 \text {. }\end{array}$ & $\begin{array}{l}\text { Os resultados indicam associação entre o EVA® e o } \\
\text { retorno de ações, embora haja maior associação entre } \\
\text { as medidas tradicionais de desempenho do que com } \\
\text { o Valor Econômico Agregado. }\end{array}$ \\
\hline Bastos et al. (2009) & $\begin{array}{l}93 \text { empresas não financeiras } \\
\text { brasileiras listadas na Bovespa, } \\
\text { no período de } 2001 \text { a } 2007 \text {. }\end{array}$ & $\begin{array}{l}\text { Utilizaram métodos de regressão para comparar o } \\
\text { retorno das ações por quatro métricas de desempe- } \\
\text { nho empresarial: Lucro por Ação, Retorno sobre o in- } \\
\text { vestimento, EVA® e Fluxo de Caixa Operacional. O } \\
\text { EVA® apresentou o pior desempenho em relação } \\
\text { aos outros modelos. }\end{array}$ \\
\hline Medeiros (2009) & $\begin{array}{l}\text { Seis companhias brasileiras no } \\
\text { período 1996-1999. }\end{array}$ & $\begin{array}{l}\text { Os resultados indicam que o EVA® afeta o retorno } \\
\text { acionário. Além disso, verifica-se que o retorno das } \\
\text { ações é influenciado pelo comportamento passado } \\
\text { do EVA®. }\end{array}$ \\
\hline
\end{tabular}


Quadro 1. Estudos anteriores sobre a relação entre o EVA® e o valor das ações

\begin{tabular}{|c|c|c|}
\hline Silva et al. (2009) & $\begin{array}{l}\text { Cinco companhias do setor de } \\
\text { energia elétrica com ações ne- } \\
\text { gociadas na BMF\&Bovespa, no } \\
\text { período de } 2007 \text { a } 2008 .\end{array}$ & $\begin{array}{l}\text { Os resultados apresentados indicam que o EVA® } \\
\text { apresentou correlação positiva com o preço das } \\
\text { ações na maior parte das companhias analisadas. }\end{array}$ \\
\hline $\begin{array}{l}\text { Arabsalehi e Mahmo- } \\
\text { odi (2011) }\end{array}$ & $\begin{array}{l}76 \text { companhias listadas na } \\
\text { Tehran Stock Exchange entre } \\
2001 \text { e } 2008 .\end{array}$ & $\begin{array}{l}\text { Os principais resultados demonstram que os retor- } \\
\text { nos das ações encontram-se mais associados ao ROA, } \\
\text { ROE e lucro por ação que o EVA®. }\end{array}$ \\
\hline Chaves et al. (2012) & $\begin{array}{l}28 \text { companhias presentes no } \\
\text { IBrX-50, no período 1998-2006. }\end{array}$ & $\begin{array}{l}\text { Os resultados apontam presença de correlação entre } \\
\text { o retorno da ação e o EVA® em apenas uma em- } \\
\text { presa, sendo ela negativa. }\end{array}$ \\
\hline Khan et al. (2012) & $\begin{array}{l}60 \text { companhias não financeiras } \\
\text { listadas na Karachi Stock Ex- } \\
\text { change, no período entre } 2004 \text { e } \\
2010 .\end{array}$ & $\begin{array}{l}\text { Os resultados mostram que tanto por meio de regres- } \\
\text { são com dados em painel como por correlação de Pe- } \\
\text { arson o EVA® contribui negativamente para o re- } \\
\text { torno de ações. }\end{array}$ \\
\hline Awan et al. (2014) & $\begin{array}{l}59 \text { empresas listadas no KSE } \\
100 \text { index, os dados coletados } \\
\text { compreendem o período de } \\
2006 \text { a } 2010 .\end{array}$ & $\begin{array}{l}\text { Os principais resultados da regressão com dados em } \\
\text { painel evidenciam a existência de relação positiva } \\
\text { entre o retorno das ações e o EVA® a um nível de } \\
\text { significância de } 10 \% \text {. }\end{array}$ \\
\hline Ray (2014) & $\begin{array}{l}36 \text { companhias listadas na } \\
\text { bolsa de valores da Índia, entre } \\
\text { os anos 2006-2009. }\end{array}$ & $\begin{array}{l}\text { Os resultados do estudo não suportam a hipótese de } \\
\text { que existe associação entre o EVA® e o preço das } \\
\text { ações. }\end{array}$ \\
\hline Khan et al. (2016) & $\begin{array}{l}28 \text { empresas não financeiras lis- } \\
\text { tadas na Karachi Stock Ex- } \\
\text { change, no período } 2009 \text { a } 2012 \text {. }\end{array}$ & $\begin{array}{l}\text { Os resultados da regressão com dados em painel de- } \\
\text { monstraram que EVA® não tem qualquer poder ex- } \\
\text { plicativo na previsão do preço das ações das empre- } \\
\text { sas paquistanesas. }\end{array}$ \\
\hline Altaf (2016) & $\begin{array}{l}325 \text { empresas indianas, não fi- } \\
\text { nanceiras, participantes do BSE } \\
500 \text { Index, no período de } 2005 \text { a } \\
2015 .\end{array}$ & $\begin{array}{l}\text { Existe associação positiva entre EVA® e capitaliza- } \\
\text { ção de mercado, mas o poder explicativo dessa mé- } \\
\text { trica é baixo e inferior ao de outras medidas contá- } \\
\text { beis, como o Resultado Operacional. }\end{array}$ \\
\hline Costa et al. (2017) & $\begin{array}{l}9 \text { companhias listadas no seg- } \\
\text { mento novo mercado do setor } \\
\text { de construção civil da } \\
\text { BM\&FBovespa, no período } \\
\text { 2010-2014. }\end{array}$ & $\begin{array}{l}\text { Em síntese, os resultados evidenciam que o EVA® e } \\
\text { o retorno da ação estão negativamente correlaciona- } \\
\text { dos, bem como que as companhias estão destruindo } \\
\text { valor no período investigado. }\end{array}$ \\
\hline
\end{tabular}

Fonte: Elaborado pelos autores

O quadro 1 evidencia três possibilidades de relação entre o EVA® e os retornos acionários: existe associação negativa entre o indicador e os retornos (Khan et al., 2012), existe associação positiva (Awan et al., 2014) e as duas métricas não possuem associação clara ou o poder explicativo do EVA® é considerado baixo (Tortella \& Brusco, 2003, Copeland et al., 2004, Ismail, 2006, Visaltanachoti et al., 2008, Bastos et al., 2009, Khan et al., 2016, Altaf, 2016). Nota-se que a maior parte dos estudos que tratam do EVA® busca evidenciar seu poder relativo em comparação com outras medidas ou sua associação ao preço, capitalização de mercado ou retorno para os acionistas. Verificase, ainda, que embora os estudos tenham sido realizados em diferentes regiões, as evidências empíricas do fenômeno não são exaustivas.

Nesse sentido, considerando o objetivo proposto neste trabalho, foi levantada a seguinte hipótese: $\mathrm{H}_{0}$ : Existe associação entre retorno das ações e Valor Econômico Agregado das empresas listadas na B3. Para testar as hipóteses levantadas nesse estudo, são realizados a correlação de Spearman e a estimação de um modelo de regressão com dados em painel. 


\section{PROCEDIMENTOS METODOLÓGICOS}

Este trabalho visa investigar a relação empírica entre o EVA® e o retorno das ações das empresas listadas na B3, tendo como referências diversas pesquisas desenvolvidas, como as de Biddle, Bowen e Wallace (1997), Copeland et al. (2004) e Bastos et al. (2009), em que a hipótese é de que o EVA® é a medida mais adequada de criação de valor e, portanto, responsável por uma vinculação entre essa medida, a criação de valor e o retorno para os acionistas.

Nesse sentido, adotou-se uma perspectiva teórico-empírica de caráter descritiva, tendo como principal intuito a descrição das características de determinado fenômeno e o estabelecimento de relações entre variáveis. As análises realizadas nesta pesquisa são de natureza quantitativa, baseada em dados secundários, obtidos na base de dados Bloomberg®.

Considera-se como população deste estudo as empresas brasileiras listadas pela B3 com dados disponíveis na Bloomberg ${ }^{\circledR}$, obtendo um conjunto inicial de 416 ativos. No entanto, alguns ajustes foram realizados para obter a amostra final. Inicialmente, foram excluídas as empresas de natureza financeira, obtendo, assim, uma amostra parcial de 238 empresas e, posteriormente foram retiradas as empresas que não apresentaram todos os dados referentes ao período analisado. Dessa forma, a amostra final desta pesquisa é de 178 empresas.

Conforme o Quadro 2, são propostas duas metodologias de cálculo dos retornos, a serem utilizados como variável dependente: o retorno contínuo, usual para os modelos de finanças, e o retorno anormal, utilizando o Modelo de Retornos Ajustados ao Mercado, encontrado em Camargos e Barbosa (2015). Esse modelo consiste em avaliar se os retornos das ações estão superando um benchmarking de mercado - neste caso, o principal índice representativo da B3, o Ibovespa.

Quadro 2. Variáveis do modelo econométrico

\begin{tabular}{|c|c|c|}
\hline Retorno Contínuo (RC) & $\ln \left(P_{t} / P_{t-1}\right)$ & Dependente, modelo 01 \\
\hline Retorno Anormal (RA) & $R C-\ln \left(I B O V_{t} / I B O V_{t-1}\right)$ & Dependente, modelo 02 \\
\hline Valor Econômico Agregado (EVA) & Lucro Líquido - (Ke X PL) & $\begin{array}{l}\text { Tortella e Brusco (2003); Ismail } \\
\text { (2006); Visaltanachoti et al. (2008); } \\
\text { Bastos et al. (2009); Medeiros } \\
\text { (2009); Khan et al. (2012); Awan et } \\
\text { al. (2014); Khan et al. (2016); Altaf } \\
\text { (2016) }\end{array}$ \\
\hline Retorno sobre o Ativo (ROA) & Lucro Líquido / Ativo Médio & $\begin{array}{l}\text { Arabsalehi e Mahmoodi (2011); So- } \\
\text { ares e Galdi (2011); Khan et al. } \\
\text { (2012); Ray (2014) }\end{array}$ \\
\hline Tamanho (TAM) & $\begin{array}{l}\text { Logaritmo natural do ativo to- } \\
\text { tal }\end{array}$ & Fama e French (1992) \\
\hline
\end{tabular}

Nota: $\mathrm{P}_{\mathrm{t}}$ é o preço do ativo na data $\mathrm{t}$; $\mathrm{P}_{\mathrm{t}-1}$ é o preço do ativo no último dia útil do período anterior; $\mathrm{IBOV}_{\mathrm{t}}$ é a cotação, em pontos, do Ibovespa na data t; IBOVt-1 é a cotação, em pontos, do Ibovespa no último dia útil do período anterior; Ke é o custo do capital próprio; PL é o patrimônio líquido, em R\$.

Fonte: os autores.

No que diz respeito ao EVA®, de acordo com Assaf Neto (2014), há vários mecanismos de cálculo, com resultados idênticos. O custo de capital próprio utilizado foi a métrica fornecida pela base de dados utilizada. De forma complementar, foram inseridas as variáveis de controle Retorno sobre o Ativo (ROA) e Tamanho, mensurado pelo logaritmo natural do Ativo Total, já utilizadas anteriormente por estudos na área que identificaram forte relação dessas variáveis com os retornos das ações, conforme evidenciado nos Quadros 1 e 2, visto que seria uma premissa muito forte assumir que o retorno das ações das empresas brasileiras seria explicado apenas pelo EVA®. 
Dois testes foram conduzidos para a escolha entre os efeitos fixos, aleatórios ou regressão na forma pooled. O teste de Hausman (1978) foi utilizado para analisar a opção entre efeitos fixos e aleatórios, sugerindo a adoção dos efeitos aleatórios para os dois modelos. O teste de Breusch-Pagan foi realizado para comparar a regressão pooled contra a com efeitos aleatórios, tendo sido confirmado o uso dos efeitos aleatórios em ambos os casos.

Para analisar se os painéis possuem raízes unitárias, foi utilizado o teste de Levin-Lin-Chu, tendo todas as variáveis sido consideradas significantes e, portanto, havendo indícios de estacionariedade dos erros, que possuem média e variância constantes.

\section{ANÁLISE DE RESULTADOS}

São apresentados nesta seção os resultados das análises estatísticas realizadas neste trabalho, inicialmente de forma descritiva e, posteriormente, demonstrando os resultados da estimação do modelo de regressão com dados em painel.

No que se refere à análise descritiva, a Tabela 1 evidencia que o retorno médio das ações da amostra tem estado negativo desde 2011, embora superando o índice padrão da bolsa de valores em diversas ocasiões, apresentado excesso em 2012, 2014 e 2015. Os valores de máximo, mínimo e o desvio-padrão permitem inferir um alto grau de heterogeneidade na amostra, dados os largos intervalos formados e a alta medida de variabilidade.

Tabela 1. Estatística descritiva das variáveis

\begin{tabular}{|c|c|c|c|c|c|c|}
\hline Variáveis & Ano & Obs. & Média & $\begin{array}{l}\text { Desvio Pa- } \\
\text { drão }\end{array}$ & Mínimo & Máximo \\
\hline \multirow{6}{*}{$\begin{array}{l}\text { Retorno } \\
\text { Contínuo (RC) }\end{array}$} & 2010 & 178 & 0,1084 & 0,3802 & $-0,8675$ & 1,7786 \\
\hline & 2011 & 178 & $-0,1662$ & 0,3930 & $-1,4666$ & 0,7869 \\
\hline & 2012 & 178 & $-0,0360$ & 0,5127 & $-2,2114$ & 0,9321 \\
\hline & 2013 & 178 & $-0,1311$ & 0,5000 & $-2,9042$ & 1,2121 \\
\hline & 2014 & 178 & $-0,2898$ & 0,4733 & $-2,0128$ & 0,6061 \\
\hline & 2015 & 178 & $-0,3367$ & 0,5911 & $-2,8278$ & 0,7928 \\
\hline \multirow{6}{*}{$\begin{array}{l}\text { Retorno Anormal } \\
\text { (RA) }\end{array}$} & 2010 & 178 & 0,0980 & 0,3801 & $-0,8778$ & 1,7681 \\
\hline & 2011 & 178 & 0,0335 & 0,3929 & $-1,2663$ & 0,9866 \\
\hline & 2012 & 178 & $-0,1073$ & 0,5127 & $-2,2827$ & 0,8607 \\
\hline & 2013 & 178 & 0,0372 & 0,4996 & $-2,7357$ & 1,3804 \\
\hline & 2014 & 178 & $-0,2602$ & 0,4732 & $-1,9832$ & 0,6356 \\
\hline & 2015 & 178 & $-0,1938$ & 0,5911 & $-2,6849$ & 0,9356 \\
\hline \multirow{6}{*}{$\begin{array}{l}\text { Valor Econômico } \\
\text { Agregado (EVA) }\end{array}$} & 2010 & 178 & 0,0118 & 1,4017 & $-6,9515$ & 14,523 \\
\hline & 2011 & 178 & $-0,1735$ & 1,9315 & $-15,737$ & 16,166 \\
\hline & 2012 & 178 & $-0,3634$ & 2,0159 & $-19,298$ & 3,0228 \\
\hline & 2013 & 178 & $-0,6587$ & 3,2639 & $-29,638$ & 3,8300 \\
\hline & 2014 & 178 & $-0,8171$ & 6,1860 & $-77,057$ & 9,8641 \\
\hline & 2015 & 178 & $-1,2628$ & 7,6124 & $-73,430$ & 4,4519 \\
\hline \multirow{6}{*}{$\begin{array}{l}\text { Retorno sobre o } \\
\text { Ativo (ROA) }\end{array}$} & 2010 & 178 & 0,0183 & 0,3550 & $-4,2906$ & 0,5428 \\
\hline & 2011 & 178 & 0,0169 & 0,2386 & $-2,8661$ & 0,4522 \\
\hline & 2012 & 178 & $-0,0035$ & 0,2746 & $-3,1105$ & 0,6442 \\
\hline & 2013 & 178 & $-0,0217$ & 0,3287 & $-3,4890$ & 0,2976 \\
\hline & 2014 & 178 & $-0,0035$ & 0,4301 & $-3,9793$ & 3,5767 \\
\hline & 2015 & 178 & $-0,0860$ & 0,5682 & $-5,6903$ & 0,2319 \\
\hline \multirow{6}{*}{ Tamanho (TAM) } & 2010 & 178 & 7,6034 & 1,8657 & 2,8192 & 13,155 \\
\hline & 2011 & 178 & 7,7352 & 1,8759 & 2,7638 & 13,304 \\
\hline & 2012 & 178 & 7,7923 & 1,8729 & 2,7537 & 13,413 \\
\hline & 2013 & 178 & 7,8368 & 1,8957 & 2,7652 & 13,531 \\
\hline & 2014 & 178 & 7,8678 & 2,0137 & 0,6124 & 13,584 \\
\hline & 2015 & 178 & 7,9073 & 2,0798 & 1,8992 & 13,710 \\
\hline
\end{tabular}

Nota: RC, RA e o ROA estão apresentados na forma decimal; EVA apresentado em R\$ milhões; TAM está apresentado na forma logaritmizada do ativo total. 
Fonte: Dados da pesquisa.

No tocante à criação de valor, os resultados evidenciam que apenas no ano de 2010 o Valor Econômico Agregado médio não foi negativo; desse modo, é possível inferir que as empresas analisadas, em média, destruíram valor durante o período de 2010 e 2015. Além disso, observa-se que a empresa que mais destruiu valor, apresenta um EVA® negativo de aproximadamente setenta e sete milhões de reais, enquanto a companhia que mais adicionou valor demonstra EVA® de aproximadamente dezesseis milhões de reais.

Por meio do Retorno sobre o Ativo, percebe-se que as empresas apresentam um retorno negativo médio de 1,32\%, onde apenas nos anos de 2010 e 2011 o valor médio do indicador foi positivo, o que evidencia que, em média, as empresas que compõem a amostra estão atingindo um nível insatisfatório de rentabilidade na utilização dos seus recursos. Por fim, em relação ao Tamanho da empresa, observa-se um logaritmo do ativo total médio das companhias de 7,79 , para o período estudado.

No intuito de verificar a correlação entre as variáveis do estudo, foi estimada a correlação de Spearman, devido à ausência de normalidade das variáveis do modelo. Os resultados estão evidenciados na Tabela 2. Verifica-se uma correlação alta e positiva, além de esperada, entre os retornos contínuos e anormais, dada a composição destes a partir daqueles.

Tabela 2. Correlação entre as Variáveis

\begin{tabular}{cccccc}
\hline Variáveis & RC & RA & EVA & ROA & TAM \\
\hline RC & 1 & & & & \\
RA & 0,9641 & 1 & & & \\
EVA & 0,2537 & 0,2387 & 1 & & \\
ROA & 0,3806 & 0,3759 & 0,6196 & 1 & \\
Tamanho & 0,0919 & 0,0901 & $-0,2965$ & 0,1741 & 1 \\
\hline
\end{tabular}

Fonte: Dados da pesquisa

No que se refere à correlação das variáveis independentes com a dependente, pode-se observar que há relação do Valor Econômico Agregado com os retornos acionários, no entanto, a variável ROA apresentou maior correlação com as variáveis dependentes. A variável Tamanho da Empresa apresentou a menor associação.

Nesse sentido, observa-se que o presente estudo apresenta evidências convergentes com os achados de Ismail (2006) e Visaltanachoti et al. (2008), uma vez que os referidos autores identificaram que o EVA® apresentou uma baixa correlação positiva com o retorno das ações.

Além disso, para identificar a relação existente entre o Valor Econômico Agregado e o retorno das ações das empresas listadas na B3, estimou-se o modelo de regressão com dados em painel. Os resultados da estimação do modelo estão evidenciados na Tabela 3.

Tabela 3. Resultados da estimação do modelo de regressão com dados em painel com efeito Aleatório

\begin{tabular}{ccc}
\hline Variáveis & $\mathbf{( 1 )}$ & $\mathbf{( 2 )}$ \\
& Retorno Contínuo & Retorno Anormal \\
\hline \multirow{2}{*}{ EVA } & $0,118^{* * *}$ & $0,0112^{* * *}$ \\
& $(0,0038)$ & $(0,0037)$ \\
\multirow{2}{*}{ ROA } & $0,2020^{* * *}$ & $0,1918^{* * *}$ \\
& $(0,0458)$ & $(0,0448)$ \\
TAM & $0,0186^{*}$ & $0,0198^{* *}$ \\
& $(0,0099)$ & $(0,0098)$
\end{tabular}




\begin{tabular}{|c|c|c|}
\hline Constante & $\begin{array}{c}-0,2780^{* * *} \\
(0,0786)\end{array}$ & $\begin{array}{c}-0,2111^{* * *} \\
(0,0784)\end{array}$ \\
\hline Observações & 1068 & 1068 \\
\hline Número de empresas & 178 & 178 \\
\hline
\end{tabular}

Os resultados dos modelos evidenciam que as variáveis EVA, ROA e Tamanho, apresentaram-se estatisticamente significantes e possuem relação positiva com o retorno das ações das empresas listadas na B3 e com o excesso de retorno em relação ao Ibovespa. Assim, verifica-se que os modelos convergem entre si, não havendo divergência de sinais.

No caso da variável EVA, observa-se que quanto maior a criação de valor, maior é o retorno da ação das companhias no período estudado, reforçando, assim, que o retorno da ação é acompanhado da geração de riqueza ao acionista (Chaves et al., 2012). Este resultado corrobora os achados de Bastos et al. (2009), Arabsalehi e Mahmoodi (2011), Awan et al. (2014) e Altaf (2016), que descrevem que o EVA® possui associação significativamente positiva com o retorno das ações.

De acordo com Awan et al. (2014), isso acontece porque os investidores estão principalmente interessados nos retornos das ações. Dessa forma, o aumento no valor econômico agregado propicia um aumento da demanda pelas mesmas, elevando, assim, o valor de mercado dessas ações.

Além disso, observa-se que, apesar do EVA® basear-se em informações contábeis históricas, essas informações são capazes de influenciar os retornos das ações calculados com base em informações que envolvem expectativas de mercado, contrapondo, assim a perspectiva de Ray (2014).

No tocante a variável de controle ROA, que também apresenta-se significante, percebe-se que quanto maior a rentabilidade, maior o retorno das ações, tendo em vista que as empresas conseguem obter lucro por meio dos seus ativos, demonstrando que a administração está sendo eficiente em gerar valor para a entidade.

Estes resultados corroboram os achados de Arabsalehi e Mahmoodi (2011) e Soares e Galdi (2011), que evidenciam a influência positiva do ROA sobre os retornos das ações nas companhias investigadas.

Uma explicação para esse fato, segundo Soares e Galdi (2011), reside no fato de que o ROA considera ativos operacionais e financeiros; assim, ao passo que as operações financeiras por parte das empresas tornam-se mais frequentes e envolvem grandes volumes de capital no contexto nacional, torna-se possível obter retornos consideráveis por meio delas. Ademais, os autores também consideram que o próprio lucro líquido utilizado no cálculo do ROA envolve ganhos provenientes de decisões financeiras, o que pode, da mesma forma, ter influência sobre o desempenho das empresas observadas.

Por fim, Fama e French (1992) argumentam que o tamanho da empresa consegue capturar a variação nos retornos das ações. Nesse sentido, os resultados desse estudo apoiam essa perspectiva, tendo em vista que a variável Tamanho se apresentou estatisticamente significante para explicar o retorno das ações das empresas listadas na B3.

\section{CONSIDERAÇÕES FINAIS}

Considerando o dissenso da literatura sobre o EVA® apresentar-se como fator explicativo para o retorno das ações, o presente estudo teve como objetivo investigar a relação empírica entre o EVA ${ }^{\circledR}$ e o retorno de ações das empresas listadas na B3.

Verificou-se que, em relação ao retorno das ações, a média das empresas analisadas apresentou um resultado negativo, ou seja, durante o período as empresas obtiveram um retorno insatisfatório em relação ao retorno do Ibovespa. Em uma mesma perspectiva, também foi percebido que, 
em média, as empresas analisadas destruíram valor em praticamente todos os anos analisados, sendo o ano de 2010 o único em que não foi apresentado um valor negativo médio do EVA®.

Os resultados do teste de correlação evidenciaram que há relação positiva do valor econômico agregado com o retorno das ações das empresas listadas na B3. No entanto, o Retorno sobre o Ativo apresentou maior correlação com a variável dependente do estudo, se apresentando como uma melhor medida de desempenho para explicar o retorno das ações, ao passo que o tamanho da empresa apresentou a menor correlação com a variável dependente.

No tocante aos resultados da regressão, percebeu-se que as variáveis EVA, ROA e Tamanho apresentaram-se estatisticamente significantes, bem como possuem relação positiva com o retorno das ações das empresas listadas na B3.

No caso da variável independente EVA, foi observado que quanto maior a criação de valor, maior é o retorno da ação das companhias no período estudado, semelhante a variável de controle ROA que apresentou-se significante e com coeficiente positivo, sugerindo que quanto maior for o Retorno sobre o Ativo, maior é o retorno das ações, levando em consideração que as empresas conseguem obter lucro através dos seus ativos. No que diz respeito à variável de controle Tamanho, observa-se que quanto maior o Ativo das empresas, maior o retorno das suas ações.

Diante disso, os resultados apresentados sugerem que existe relação entre o EVA®, o ROA e o Tamanho da empresa com o retorno das ações das empresas listadas na B3, de forma que não foi possível rejeitar a hipótese nula. Nesse sentido, este estudo contribui para análise dessas medidas de desempenho na geração de valor das empresas, buscando esclarecer a divergência existente na literatura sobre a relação dessas medidas com o retorno das ações.

O resultado sugere que há importância em monitorar o Valor Econômico Agregado, considerando que há indícios de ser um componente precificado na composição dos retornos, inclusive quanto a sinalização de que a firma tem capacidade para possuir um retorno que excede a um índice referencial da bolsa de valores, o que é desejável para os investidores.

Do ponto de vista da gestão da companhia, o resultado reforça a importância do acompanhamento desse indicador, de forma a favorecer a seleção da empresa em um mercado que compete pela captação de recursos de particulares.

Como contribuição teórica do presente estudo, verificou-se que os modelos para retornos contínuos e retornos anormais são convergentes. Além disso, demonstrou-se que o EVA $®$, para companhias brasileiras não-financeiras, pode ser utilizado como uma métrica para medição de desempenho, uma vez que essa relaciona-se positivamente com o retorno das ações. Além disso, em relação às contribuições metodológicas, foram inseridas, nos modelos propostos, variáveis de controle, fato esse não contemplado nos demais estudos nacionais na área - Bastos et al. (2009) e Medeiros (2009).

No tocante às limitações, cita-se o viés de seleção, na medida em que foram incluídas apenas companhias com dados disponíveis na plataforma Bloomberg®. Além disso, os resultados não são extensíveis ao setor financeiro, uma vez que esse não foi incluído no presente estudo.

Como proposições para estudos futuros, sugere-se analisar a relação de outras métricas de desempenho que utilizem o conceito de lucro econômico, com o retorno das ações, bem como a relação do Valor Econômico Agregado com os níveis de governança corporativa das companhias. Ademais, considera-se interessante a elaboração de novas pesquisas acerca dos efeitos do EVA® sobre os retornos de empresas do setor financeiro a fim de confirmar os achados para a totalidade do mercado, considerando que as empresas desse setor não foram inseridas na amostra do estudo.

\section{REFERÊNCIAS}

Arabsalehi, M., \& Mahmoodi, I. (2011). EVA® or traditional accounting measures: Empirical evidence from Iran. International Research Journal of Finance and Economics, 65, 51-58. 
Assaf, A., Neto. (2014). Valuation: métricas de valor e avaliação de empresas. São Paulo: Atlas.

Altaf, N. (2016). Economic value added or earnings: What explains market value in Indian firms? Future Business Journal, 2(2), 152-166.

Awan, A. G., Siddique, K., \& Sarwar, G. (2014). The effect of Economic Value Added on stock return: Evidence from selected companies of Karachi stock exchange. Research Journal of Finance and Accounting, 5(23), 140-153.

Bastos, D., Nakamura, W., David, M., \& Rotta, U. (2009). A relação entre o retorno das ações e as métricas de desempenho: evidências empíricas para as companhias abertas no Brasil. Revista de Gestão da USP, (16)3, 65-79.

Biddle, G., Bowen, R., \& Wallace, J. (1997). Does EVA® beat earnings? Evidence on associations with stock returns and firm values. Journal of Accounting and Economics, 24(3), 301-336.

Burksaitiene, D. (2009). Measurement of value creation: Economic Value Added and net present value. Economics \& Management, 14(1), 709-714.

Camargos, M. A., \& Barbosa, F. V. (2015). Eficiência informacional do mercado de capitais brasileiro em anúncios de fusões e aquisições. Production, 25(3), 571-584.

Cerqueira, J., Soares, T., \& David, M. (2009). Novas evidências sobre a relação entre a geração de valor ao acionista e o valor de mercado das ações: uma análise em painel comparando o EVA® e o MVA® no mercado brasileiro. Pesquisa Operacional para o Desenvolvimento, 1(2), 178-196.

Chaves, E. P. S., Vellani, C. L., \& Pimenta, T., Jr. (2012). Ausência de correlação positiva entre retorno da ação e desempenho econômico EVA® das empresas do IBrX 50 da BOVESPA. Revista de Administração IMED, 2(2), 118-128.

Copeland, T., Dolgoff, A., \& Moel, A. (2004). The role of expectations in explaining the cross-section of stock returns. Review of Accounting Studies, 9(2), 149-188.

Costa, F. H.; Silva, M. R. V.; Sampaio, R. M. A.; \& Tavares, A. L. (2017). Análise da Criação de Valor por meio do Eva ${ }^{\circledR}$ e o Retorno das Ações das Companhias Real Estate no Brasil. Revista Científica Hermes, 17, 1-20.

Duarte, S. C. J. S. (2011). Avaliação da performance empresarial: o Economic Value Added (EVA®) e a sua relação com o valor da empresa. Dissertação de Mestrado, Instituto Superior de Contabilidade e Administração de Lisboa, Lisboa, Portugal.

Fama, E. F., \& French, K. R. (1992). The cross-section of expected stock returns. The Journal of Finance, $47(2), 427-465$.

Haddad, F. S. (2012). The Relationship between Economic Value Added and stock returns: Evidence from Jordanian banks. International Research Journal of Finance and Economics, 89, 6-14.

Haque, M. R., \& Islam, M. F. (2013). Economic Value Added as measurement tool of financial performance: A case study of square pharmaceuticals limited. Journal of Science and Technology, 11(1), 17-20.

Hausman, J. (1978). Specification tests in econometrics. Econometrica, 46(6), 1251-1271.

Ismail, A. (2006). Is Economic Value Added more associated with stock return than accounting earnings? The UK evidence. International Journal of Managerial Finance, 2(4), 343-353. 
Khan, U. A., Aleemi, A. R., \& Qureshi, M. A. (2016). Is Economic Value Added more associated with stock price than accounting earnings? evidence from Pakistan. City University Research Journal, 6(2), 204-216.

Khan, M. A., Shah, N. H., \& Rehman, A. (2012). The relationship between stock return and Economic Value Added (EVA): a review of KSE-100 Index. AABRI Conference Paper.

Kim, W. G. (2006). EVA and traditional accounting measures: which metric is a better predictor of market value of hospitality companies?. Journal of Hospitality ETourism Research, 30(1), 34-49.

Medeiros, O. R. (2009). Evidências empíricas sobre a relação entre EVA e Retorno Acionário nas empresas brasileiras. Contabilidade, Gestão e Governança, 12(1), 3-9.

Mosavai, S. M. K. (2015). Application of Economic Value Added (EVA) in stock return evaluation of accepted oil productions companies in the Tehran stock exchange (TSE). The Caspian Sea Journal, 9(1), 74-80.

Mostafa, W., \& Dixon, R. (2013). The impact of earnings extremity on information content of cash flow. Review of Accounting and Finance, 12(1), 81-104.

Nakhaei, H., Hamid, N. I. N., Anuar, M. A., \& Nakhaei, K. (2016). Is refined economic value added more associated with stock return than accounting measures? The Malaysian evidence. Society and Economy, 38(1), 69-85.

O'Byrne, S. F. (1997). EVA and shareholder return. Financial Practice and Education, 7(1), 50-54.

Palliam, R. (2006). Further evidence on the information content of the Economic Value Added. Review of Accounting and Finance, 5(3), 204 -215.

Ray, K. K. (2014). EVA as a Financial Metric: the relationship between EVA and Stock Market Performance. European Journal of Business and Management, 6(11), 105-114.

Silva, A. M. G., Lagioia, U. C. T., Leismann, E. L., Miranda, L. C., \& Maciel, C. V. (2009). Análise da Relação entre o Preço das Ações na Bolsa de Valores e Indicadores Contábeis: Um Estudo Aplicado a Empresas do Setor de Energia Elétrica. Revista de Negócios, 14(2), 52-70.

Shah, R., Haldar, A., \& Rao, S. V. D. (2015). Economic Value Added: Corporate performance measurement tool. Corporate Board: Role, Duties \& Composition, 11(1), 47-58.

Sharma, A. K., \& Kumar, S. (2012). EVA versus conventional performance measures-empirical evidence from India. Proceedings of ASBBS, 19(1), 804-815.

Soares, R. E., \& Galdi, C. F. (2011). Relação dos modelos DuPont com o retorno das ações no mercado brasileiro. Revista Contabilidade \& Finanças, 22(57), 279-298.

Stewart, G. B. (1994). EVA: fact and fantasy? Journal of Applied Corporate Finance, 7(2), 71-84.

Tamamy, E., \& Awad, M. (2014). Investigating the explanatory power of economic profits (EVA®) versus accounting profits on stock returns as a measure of shareholders wealth creation: An empirical study of the FTSE 100. Dissertação de Mestrado, London School of Business \& Finance, London, England.

Tortella, B., \& Brusco, S. (2003). The Economic Value Added (EVA): an analysis of market reaction. Advances in Accounting, 20(1), 265-290. 
Visaltanachoti, N., Luo, R., \& Yi, Y. (2008). Economic Value Added (EVA®) and sector returns. Asian Academy of Management Journal of Accounting and Finance, 4(2), 21-41.

Young, S. D., \& O' Byrne, S. F. (2003). EVA e gestão baseada em valor: guia prático para implementação. São Paulo: Arimed. 